Article

\title{
Getting in the Flow Together: The Role of Social Presence, Perceived Enjoyment and Concentration on Sustainable Use Intention of Mobile Social Network Game
}

\author{
Huimin Wang and Kyungtag Lee * \\ School of Business, Yeungnam University, 280 Daehakro, Gyeongsansi 38541, Gyeongsangbukdo, Korea; \\ 15210673827@ynu.ac.kr \\ * Correspondence: marketing@ynu.ac.kr; Tel.: +82-53-810-2739
}

Received: 10 July 2020; Accepted: 20 August 2020; Published: 24 August 2020

check for updates

\begin{abstract}
Mobile Social Network Games (MSNGs) are defined as a product that combines games and social network services (SNSs). Compared with games played individually, MSNGs offer additional enjoyment to users through competition or cooperation. Mobile phone games, which rely on SNS platforms, can develop a strong social presence for users. This study focuses on factors affecting the sustainable use intention of MSNGs. In our study, we chose social presence as our dependent variable and proved that the social presence perceived by players in MSNGs has a positive impact on the sustainable use intention through a series of mediator variables. Second, the game product itself can easily lead to player addiction; therefore, in this study, we use the flow theory-perceived enjoyment and concentration - as our mediator variables. The results showed that perceived enjoyment and concentration are important factors driving the attitude towards MSNGs and that attitude presents a significant positive effect on sustainable use intention. This study enhances the current understanding of sustainable use intention of MSNGs and provides practical implication for MSNG development strategies and the theoretical implication.
\end{abstract}

Keywords: MSNGs; social presence; perceived enjoyment; concentration

\section{Introduction}

Along with the dramatic improvement of mobile devices, smartphone-based social network service (SNS) enables users to interact electronically with others anytime and everywhere, and allows people to maintain intimate and close relationships [1,2]. For this reason, mobile game providers also have begun to design and provide mobile social network games (MSNGs), which constitute a new kind of mobile game that combines SNS and mobile game features [2,3]. These games all have an important characteristic that they are played on mobile devices and can connect with their mobile SNS applications to play with their friends together [4]. Hence, players not only can enjoy the game, but they can also enhance their relationships with others while playing MSNGs together [2,3].

MSNGs have indeed achieved great success and are amongst the most popular game types played in the world currently, and include many products with tens of millions of players [2]. For example, 'Candy Crush Saga,' 'Arena of Valor,' and 'Farm Ville' are examples of popular mobile social network games. 'Candy Crush Saga' is one of the best-known mobile social network games around the world. It has 272 million monthly active players and in 2018, this game reportedly had its highest grossing 12 months since launch, raking in an estimated $\$ 930$ million of revenue [5].

Despite the success of MSNGs, only a few studies have been done on MSNGs, and most of their research focuses on the motivation as to why people like to play MSNGs based on extended 
TAM(Technology Acceptance Model) [3,6,7]. Wei and Lu [6] proposed that the perceived number of users and individual gratification can influence the willingness of people to join an MSNG. Park et al. [3] also examined player's acceptance and attitudes toward MSNGs based on an extended TAM. They proposed perceived mobility, perceived control, and perceived skill as the motivators for users to play an MSNG. Chen et al. [7] also proposed an extended TAM model and added several additional variables, such as social interaction, altruism, and enjoyment to understand a user's intention to play an MSNG based on SNS.

Regarding prior research, we can note that researchers mostly used extended TAM models to explain the reason why users join an MSNG. Compared to other mobile games, MSNGs provide various social features by which users can engage with their SNS friends in either a competitive or collaborative manner [8]. Previous research regarding social features of MSNG has been scarce. Few studies have investigated social features of MSNG and its effect on sustainable use intention. We propose that these social features would be an important reason as to why people sustainably intend to play MSNG. As mentioned in previous literature, a few users might not particularly enjoy mobile gaming, but still use it to sustain a social relationship or attempt to gain social presence [9]. Also, many mobile game providers consider social networking features as key to retaining players [10]. There are, however, still some gaps in the research of how social features motivate a player's MSNG sustainable use intention. Therefore, it is necessary to examine the implications of these social features of MSNG and how it affects a person's sustainable use intention.

MSNGs can serve as a form of social media that enable users to perceive social presence in mutual interactions [11]. Social presence means the sense of "being together" psychologically [1]. Weibel et al. [9] also noted that mobile games, which rely on SNS platforms, can create a strong sense of social presence for users. The MSNG environment provides further usefulness to the users by facilitating and promoting their social presence during gameplay. Moreover, MSNGs can be advertised effectively via users' social networks because of the inherent social features. Therefore, users are naturally inclined to attract other players to their games [8] and we propose that it will enhance player's sustainable use intention for MSNG.

We also propose that as a psychological state of 'being together,' social presence will influence flow and through that affect the sustainable use intention. We consider flow-perceived enjoyment and concentration-as our mediating effect variable in our study. Flow in the game refers to the sensation of being involved in the gaming action [11]. Park and Hwang [12] found that players keep on playing online games if they experience something commonly known as flow. In previous literature, researchers have proven the connection between social presence and flow. Bachen et al. [11] established social presence as an antecedent to flow, and they tested the relationship between flow and playing intentions of computer games. However, few studies have explored such issues in MSNGs, therefore the current study has a significant contribution to the field.

The present study proposes a new model that can be applied to investigating the sustainable use intention of MSNGs. It allows us to understand the important role of perceived social presence in playing MSNGs, and from a theoretical perspective we examined how perceived social presence can lead to sustainable use intention, that is, social presence can activate a state of flow through perceived enjoyment and concentration.

This study examines our premises in the MSNGs context to ensure that the findings make contributions for both academics and practitioners.

\section{Literature Review}

\subsection{Mobile Social Network Games}

The growth of mobile social network services worldwide has radically transformed how people use the cyberspace. It has also altered the lifestyles of individuals, changed the landscape of business activities, and led to the emergence of various social platform-based services. Social platform services 
have leveraged the popularity of smart mobile devices to create more innovative products such as social network games (SNGs) [3]. SNGs are a type of browser game which are distributed mainly via social networks [8]. Different from casual online games, SNGs are much more about the 'social' aspect than the 'game' aspect. Rather than focusing on the game itself, the aim of SNGs is to create and expand people's social networks with social-media platforms [13]. Initially, SNGs were played on SNS platforms through a simplified mode, memory minimization, simple operation, etc. Also, they are different from other games as they are characterized primarily by their social features and association with social networks.

Users play SNGs in either a competitive or collaborative fashion with other players and frequently interact with other users within the game, many of whom may be seen as their friends on certain SNSs. In addition, users can also send out invites or gifts to other players, while social rankings are displayed in multiple ways so users can compare their performance with that of their friends [6]. People are increasingly dependent on smart phones, and SNS activities have also shifted from computers to smartphones. Game developers have combined mobile games with SNS, resulting in the birth of MSNGs.

MSNG is a kind of mobile game played online that utilize a player's social-network-based mobile device [8]. MSNG is a broad concept that integrates social, network, and mobile games. Unlike mobile gaming played in isolation, mobile social games are developed to be enjoyed and shared with friends through existing social networking platforms in conjunction with smartphones [14]. As mobile devices are essentially used for social communication, they are commonly offered with one or more SNS platforms, such as Facebook, WhatsApp, WeChat, etc. MSNG means a new type of product that combines existing mobile game and SNS in such a powerful way that games are used as a tool for developing, managing, and promoting social relations among authorized users. These games offer users increased utility to enable and facilitate their social presence during gameplay [6]. In addition, due to the intrinsic social characteristics of MSNGs, they can be effectively promoted via the users' social networks so that users are naturally inclined to pull in other friends into their games [6].

With the second largest gross domestic product (GDP) in the world and a population of 1.4 billion, China's game market is very attractive for many game developers. According to the "GPC\&CNG 2018 China Gaming Industry Report" [15], China has 626 million game users and 605 million mobile game users. Moreover, the game market revenue was $\$ 30$ billion, accounting for $23.6 \%$ of the world total, which makes it the biggest game market globally. Mobile game sales are $\$ 18.75$ billion, accounting for $62.5 \%$ of China game market revenue and $30.8 \%$ of the global mobile game market. China's top two mobile games are 'Arena of Valor' and 'Player Unknown's Battlegrounds' (developed by Tencent). These two MSNGs are connected with SNS platforms such as WeChat and QQ, which gives them enormous virality (www.cgigc.com.cn). In our research, we used a questionnaire survey to examine these two games. China is increasingly attracting developers and investors around the world as a glamorous market, and the SNS software that has the most users in China is WeChat (developed by Tencent), which is also the third-ranked SNS software (after only WhatsApp and Facebook) in the world. According to the WeChat Impact Report 2018 [16], in China, WeChat users have reached 1000 million. Tencent, the developer of WeChat, has been working diligently to develop mobile games that connected with the WeChat platform. We hope to study the combination of SNS with the success of mobile games to provide new ideas for more game developers and investors.

\subsection{Social Presence}

Social presence is the original concept of presence theory developed by John Short and his colleagues. Short et al. [17] conceptualized that social presence refers to the level of a person's ability to remain relevant in a social setting. It is not unusual to have a different social presence because of the difference in auditory, visual, and physical contacts with different media. Furthermore, Short et al. [17] pointed out that social presence is also closely related to intimacy and closeness in a psychological sense. Therefore, social presence is frequently measured as the perceived warmth, expressing a 
feeling of human sociability, sensitivity, and contact embodied in an instrument [18]. Park and Hwang [12] view social presence as "an experiential sense of users in mediated communication contexts." Animesh et al. [19] conceptualized social presence as "the perceived sense of how personal, warm, intimate, sociable, or sensitive the social interactions are in a virtual environment." According to the media richness theory, the higher the perceived social presence, the more 'real' the feeling is and therefore the more a person can indulge in an activity. Also, Animesh et al. [19] found that high social presence makes people evoke identity-related behaviors. It is not uncommon for participants with high social presence to invest more in consuming virtual products [19]. In the previous research, researchers found that when people perceive a high social presence, they have a positive attitude to continue use behavior, such as with online games [12,20], online learning [21], SNS use [1,22], and online shopping [18]. With the connection of online games and SNS platforms, therefore, it is believed that perceived social presence has a direct and indirect effect on the sustainable use intention of MSNG players.

The theory of social presence explains how individuals communicate with others through different media, and it shows how social presence can help these media achieve success [21]. To research how online game communities retain gamers, Tseng et al. [20] pointed out that the popularity of high-speed Internet and advances in multimedia technology have made online games a vivid medium for gamers to experience powerful social presence. Similarly, for MSNGs, social media sharing allows game connectivity regardless of the time zone or geographical location of the player. In addition, ubiquitous connectivity enables people to develop and maintain an intimate relationship with other players, thus improving social presence [1].

In sum, social presence facilitates communication and enhances the development and maintenance of interpersonal relationships among online game players.

\subsection{Flow Theory}

Csikzentmihalyi and Lefevre [23] argue that flow is the holistic feeling that is experienced by people when they are totally involved in an activity. They also describe people's sensation when they are actively participating and immersed in an activity. Flow can be experienced in a variety of common activities such as reading, watching a movie, or engaging in sports [24]. It is also suspected that those people who enjoy flow experience may develop a tendency to repeat the behavior during an activity [25]. In a flow state, time may seem to stand still when people are engaged in an activity [26]. Extensive evidence shows that users have been attracted by the flow experience and their subsequent attitudes and usage behaviors have also been significantly affected. Park et al. [27] also claimed that flow influences satisfaction and performance of activities in different areas such as playing sports, engaging in hobbies, and business activities. If users experience flow, they experience greater enjoyment, expect to enjoy this experience again, and therefore continue to use. Novak et al. [28] argue that online flow can be felt when a user is completely engulfed in an online activity. Online flow has been suggested as the core process in a user's internet navigation [29], program usage [25], online shopping [30], and online gaming $[12,31]$. In a study of flow experience using professional team sport web sites, O'Cass and Carlson [32] acknowledged that when perceived flow state is experienced pleasurably, they would want to re-experience it as many times as possible. Chiang et al. [31] found that if people have the optimal experience commonly known as the concept of flow, they want to continue to play online games. We believe that many features of MSNGs instigate flow states, including the enjoyment, playfulness, allowing expressive and instantaneous feedback to player actions, and capability to invoke higher user focus. Table 1 shows the many characteristics of flow previously summarized by researchers. 
Table 1. Prior research on the characteristics of flow.

\begin{tabular}{|c|c|c|}
\hline Reference & Context & Summary of Flow \\
\hline [23] & Happiness and how to find it & $\begin{array}{l}\text { Balance challenge and skill in a task will } \\
\text { lead flow; a task should have clear goals; } \\
\text { a task provide immediate feedback }\end{array}$ \\
\hline [33] & $\begin{array}{l}\text { Contract with computer communication } \\
\text { and mediated communication }\end{array}$ & $\begin{array}{l}\text { Perceived control, curiosity, attention } \\
\text { focus, and intrinsic interest }\end{array}$ \\
\hline [25] & Flow in human-computer interactions & $\begin{array}{l}\text { Intrinsic interest, curiosity, a combination } \\
\text { of intrinsic interest and curiosity }\end{array}$ \\
\hline$[34]$ & Computer use in working content & Total concentration, enjoyment \\
\hline$[30]$ & $\begin{array}{l}\text { Online consumer behavior (both shopper } \\
\text { and computer user) }\end{array}$ & $\begin{array}{l}\text { Intrinsic enjoyment, perceived control, } \\
\text { concentration/attention focus }\end{array}$ \\
\hline [35] & Website sticking & $\begin{array}{l}\text { Focused attention, control, curiosity, } \\
\text { temporal dissociation }\end{array}$ \\
\hline$[36]$ & Instant Message user behaviors & Perceived enjoyment, attention focus \\
\hline [37] & Web 2.0 virtual social network use & Perceived enjoyment, attention focus \\
\hline [38] & $\begin{array}{l}\text { Players' loyalty in mobile } \\
\text { game applications }\end{array}$ & Perceived enjoyment, attention focus \\
\hline$[24]$ & Social media use & $\begin{array}{l}\text { Enjoyment, concentration, challenge, } \\
\text { control, curiosity }\end{array}$ \\
\hline [39] & Online store atmospheric color & Enjoyment, concentration \\
\hline
\end{tabular}

In this research, we operationalized the concept of flow with two dimensions: perceiver enjoyment and concentration, which are also the main mediator variables in our research model. Perceived enjoyment and concentration are believed to be directly linked to game playing. As shown in Table 1, these two dimensions are frequently observed in computer-human behavior research as core characteristics of online flow and have received considerable attention in marketing research. Previous research has shown that concentration and enjoyment are enough to display the flow of people in a human-machine environment. Therefore, the two-dimensional structure seems to be simplistic enough to capture the full flow experience in an MSNG environment.

Perceived enjoyment as an internal motivation has been defined as the degree of perceived pleasure in a virtual world [24]. It captures the individual's sense of subjective satisfaction with technology interaction [34]. In mobile SNS research, perceived enjoyment reflects the pleasure users feel, and concentration indicates the level of user immersion in the activity [40]. When playing MSNGs, experience enjoyment is the most important purpose for players. In our study, we suggest that perceived enjoyment reflects the pleasure state and concentration reflects player immersion while playing MSNGs.

On the other hand, Novak et al. [28] used cognitive concentration, which is defined as the extent to which an individual is immersed in an activity, to measure the flow experience of mobile TV users. Koufaris [30] reported that an individual in 'flow' concentrates on their activity without any distraction. Concentration also plays a key part in user behavior displayed online. Webster et al. [25] claimed that flow-measured concentration has a positive effect on sustainable use intention in using a service again. In addition, Jung et al. [41] also empirically proved the beneficial linkage between the concentration and the usage intention of watching TV on mobile devices.

In our research, we suggest that social presence positively influences perceived enjoyment and concentration through playing MSNGs, and that players that experience flow have a positive attitude to the MSNGs. 


\section{Research Model and Hypotheses}

Figure 1 shows the research model to understand the role of enjoyment and concentration on attitude and the effect of attitude on sustainable use intention of mobile network based on the SNS.

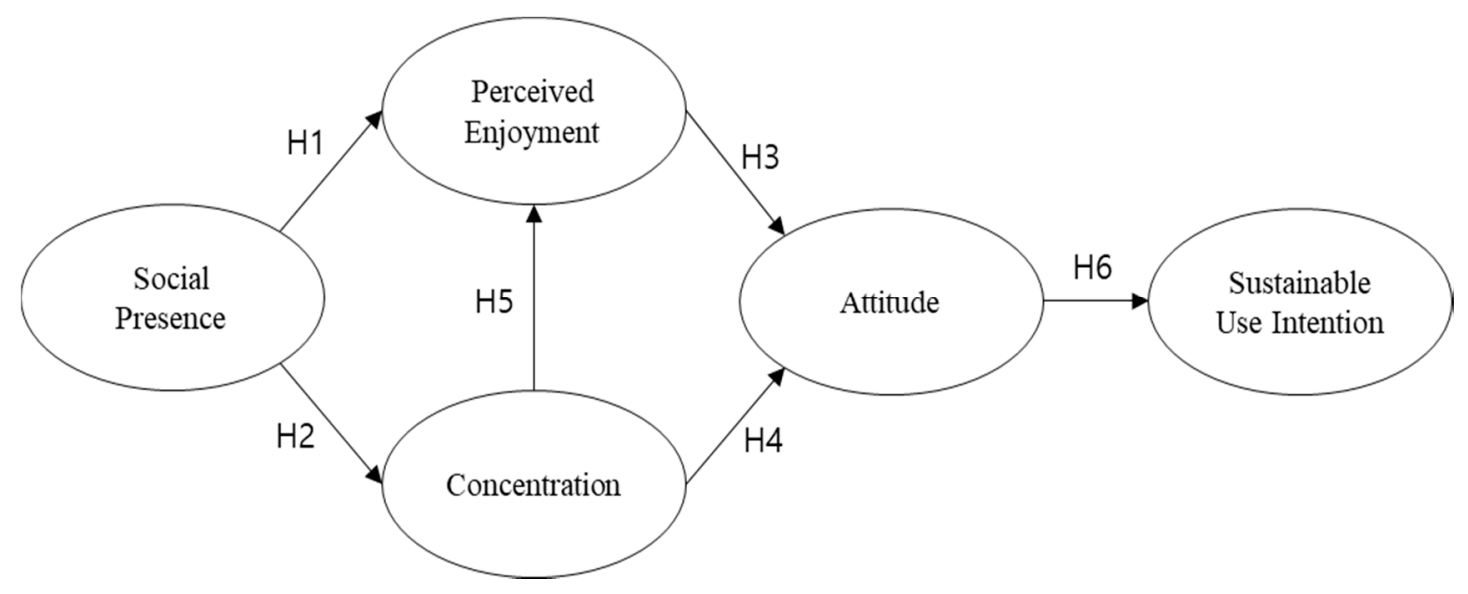

Figure 1. Research model.

\subsection{Social Presence with Flow}

In our research, we operationalized the concept of flow with two dimensions: perceived enjoyment and concentration. We proposed that social presence perceived by an MSNG player has a positive relationship with perceived enjoyment and concentration.

\subsubsection{Social Presence with Perceived Enjoyment}

In some areas evidence has proven the link between social presence and perceived enjoyment; however, few studies have examined the relationship between the two variables in game use areas. In virtual learning environments, social presence is an explanatory factor that influences the learners' enjoyment as well as satisfaction [42]. Another study regarding virtual golf simulators indicates that social presence significantly affects perceived enjoyment [43]. Heeter [44] also observed that the greater the users' enjoyment, the greater the social presence felt by users in the context of a virtual reality entertainment system. Therefore, in this study we expect that when users experience MSNGs, perceived enjoyment will increase due to social presence. Furthermore, both social presence and perceived enjoyment are prevalent in experiencing flow. Animesh et al. [19] found that the flow experience is increased through the induced psychological proximity by social presence. This implies that the internal enjoyment is developed by virtual environment engagement. Thus, we can infer that people have fun and gain pleasure through SNS-based games when they feel social presence (i.e., warmth and interpersonal actions with others). The main reason for using SNG is that it can enable a form of relationship development and maintenance thereof. Then, users who perceive social presence when playing mobile SNG are more likely to enjoy it. Therefore, our first hypothesis is stated as:

Hypothesis 1 (H1). Social presence has a positive relationship with perceived enjoyment.

\subsubsection{Social Presence with Concentration}

Concentration, one of the most significant components of flow, can be defined as the extent to which the individual's attention is completely immersed in the activity to the degree that nothing else matters to the person [24]. Recently, concentration is expected to have a relation with online games [45,46]. Chiang et al. [31] claimed that online games have a multitude of aspects that can stimulate flow states, such as instantaneous and plentiful feedback to player activities, playfulness, 
enjoyment, as well as forming higher player concentration. In our research, we mainly study whether the concentration state of a user playing an MSNG has an impact on their attitudes to play the games. While playing games, a user's attention focus is on the action and non-relevant thoughts and observations are filtered out since their focus is on a limited stimulus field. Therefore, the person may lose self-awareness, be engrossed in the activity, and become continuously and more intensely aware of their cognitive processes. The person's attention will focus on the interactions if the person falls into a playful state during the interaction with the MSNG [47].

Jin [48] claims that flow is the optimal experience resulting from social presence. Steuer [49] conceptualizes social presence as the sense of being within a certain environment. In other words, the sense of being in a far-off place is the ability to sense another's existence in a setting which is mediated by a communication vehicle. Social presence in online games is described by the perceived sense of how personal, warm, intimate, sociable, or sensitive the social interactions are in the virtual environment. The higher the perceived social presence, the more 'real' the feeling is and the more a person can indulge in an activity. In MSNGs, people interact in the game world with acquaintances and friends. This interaction affects the perceived social presence, which in turn influences deeper concentration. So, in our research we suggest that social presence has a positive influence on concentration. Hence, our next hypothesis is as follows:

Hypothesis 2 (H2). Social presence has a positive relationship with MSNG concentration.

\subsection{Flow with Attitude}

Many studies have found that flow experience or flow state has a positive effect on attitude (online games [31]; mobile social networking services [40]; online lesson [28]). In our research, we also proposed users experiencing flow in playing MSNGs gain a positive attitude to this game.

\section{Perceived Enjoyment with Attitude}

Playing games is a form of hedonism [50], and people play games partly to enjoy a memorable experience. Ha et al. [51] argue that perceived enjoyment naturally should make part of a game's basis. Enjoyment can be regarded as the level of satisfaction of participating in an activity. It is seen as a crucial factor for entertainment media (such as games) as individuals who consume these types of entertainment mainly seek out fun or pleasure from this activity [52]. Perceived enjoyment with regard to mobile gaming can be described as the reach of a game's enjoyableness through mobile devices [52]. It is a fundamental factor in the prediction of people's attitudes toward behavioral intentions and actual usage in the context of hedonic SNS game behavior [1].

The perceived enjoyment is an important factor in experiencing entertainment games, and it has been extensively examined. Several studies have reported the influence of perceived enjoyment on players' attitudes [53]. Lu et al. [54] indicate that perceived enjoyment has a positive as well as significant effect on users' attitudes. Ha et al. [51] also find that perceived enjoyment has a positive influence on users' attitudes in playing games. Given that MSNGs are a kind of hedonic experience enjoyed by players through game-based mobile phone SNS platforms, we can assume that the attitude towards this game is positive. Hence, we state the third hypothesis:

Hypothesis 3 (H3). The perceived enjoyment of MSNG has a positive relationship with the attitude towards the MSNG.

\subsection{Concentration with Attitude}

Novak et al. [28] have established that flow produces positive attitudes. In order for users to reach a flow state, they firstly must focus on the action at hand completely [55]. In the research for SNS use motivation of $\mathrm{Wu}[56]$, they suggest that concentration as an element of flow is linked to SNS attitude. 
Sweetser and Wyeth [45] found that the more concentration a task demands in the form of attention, the more absorbing the task will become. If game players cannot focus on the game, they will not be able to experience flow. In other words, the key to making people be in the flow is ensuring that they are completely immersed in the game. Hence, we propose the following hypothesis.

Hypothesis 4 (H4). Concentration has a positive relationship with the attitude towards MSNG.

\section{Perceived Enjoyment with Concentration}

Perceived enjoyment and concentration have been researched as the elements of flow theory. Liu and Li [46] note that the users may feel the greatest enjoyment when they are inevitably absorbed in playing mobile games. That is, perceived enjoyment is positively influenced by cognitive concentration while a user is playing mobile games. Sweetser and Wyeth [45] studied how to evaluate player enjoyment in games, which they assumed to be enjoyable, and concentration is also been required in a game. In other words, the players must be able to focus on the game. Chinchanachokchai et al. [57] acknowledge that when people are fully concentrated on some activities, time seems to run very fast and so too does the enjoyment felt during the activity. Thus, we posit the following hypothesis.

Hypothesis 5 (H5). Concentration has a positive relationship with perceived enjoyment of MSNG.

\subsection{Attitudes Towards MSNG Which Influences Sustainable Use Intention}

The Theory of Reasoned Action (TRA) assumes that the outcome of an individual's specific behavior is formed by his or her behavioral intentions, which is influenced both by the person's attitudes as well as subjective norms [14]. The TRA defines an attitude towards a behavior as an individual's positive or negative feeling in performing the target behavior. Many researchers have shown that a positive attitude always induces a high behavioral intention. Use intention, also known as the flow consequence, refers to a form of post-adoption behavior [58]. Many studies have proved that positive attitude has a direct effect on sustainable use intention in many areas (e-learning [59]; Facebook use [60]; online games [61]). In this research, we investigate only players who have experience with MSNG games. As for short-lived SNG games, the key to success is the continuous use behaviors caused by the player's sustainable use intention. Therefore, we speculate that regarding players who have experience with games, a positive attitude towards the game causes their sustainable use intention. Thus, we propose the following hypothesis.

Hypothesis 6 (H6). Attitude towards MSNG has a positive relationship with the sustainable use intention.

\section{Research Methodology}

\subsection{Data Collection and Measures}

An online questionnaire survey in China was conducted to test the proposed model and hypotheses. We chose two relatively mature games in China. One is Arena of Valor, the other is Player Unknown's Battleground. We randomly distributed our questionnaire on the online survey website: www.wjx.cn. Social presence was measured with five items adopted from [1]. Perceived enjoyment was measured with three items from [14,24]. Concentration was measured with three items used by [46]. Attitude was measured with three items adopted from [14]. MSNG is a game service area characterized by the sustainable use of the social network service. From the view of the principle of maintenance, we consider the sustainable use intention to be similar to continuous use intention in this study. Therefore, sustainable use intention adopted continuous use intention, and it was measured with two items from $[14,62,63]$. All measurement items can be found in Table 2. 
Table 2. Measurement items.

\begin{tabular}{|c|c|c|}
\hline Construct & Measurement Items & Reference \\
\hline Social Presence (SOP) & $\begin{array}{l}\text { SOP1: When playing MSNG, the interaction with the } \\
\text { other users is personal } \\
\text { SOP2: When playing MSNG, the interaction with the } \\
\text { other users is warm } \\
\text { SOP3: When playing MSNG, the interaction with the } \\
\text { other users is close } \\
\text { SOP4: When playing MSNG, the interaction with the } \\
\text { other users is humanizing } \\
\text { SOP5: When playing MSNG, the interaction with the } \\
\text { other users is emotional }\end{array}$ & [1] \\
\hline Perceived Enjoyment (PEE) & $\begin{array}{c}\text { PEE1: I enjoy playing MSNG } \\
\text { PEE2: I find MSNG enjoyable and fascinating } \\
\text { PEE3: I feel exciting when I play MSNG }\end{array}$ & {$[14,24]$} \\
\hline Concentration $(\mathrm{CON})$ & $\begin{array}{c}\text { CON1: During the playing of an MSNG, I am usually } \\
\text { intensely absorbed in the activity } \\
\text { CON2: During the playing of an MSNG, I concentrate } \\
\text { fully on the activity } \\
\text { CON3: During the playing of an MSNG, I am deeply } \\
\text { engrossed in the activity }\end{array}$ & [46] \\
\hline Attitude (ATT) & $\begin{array}{l}\text { ATT1: I would have positive feelings towards MSNGs } \\
\text { in general } \\
\text { ATT2: I think playing MSNG is not appeal to me } \\
\text { ATT3: It would be a good idea to play MSNG }\end{array}$ & [14] \\
\hline Sustainable Use Intention (SUI) & $\begin{array}{l}\text { SUI1: I intend to visit MSNG apps as much as possible } \\
\text { SUI2: I intend to continue playing MSNG in the future }\end{array}$ & {$[14,62,63]$} \\
\hline
\end{tabular}

A total of 237 questionnaires was collected using an online survey site during about the course of one week during December 2018. Table 3 shows the demographics of sample. Among the respondents, $53.6 \%$ were male and $46.4 \%$ were female. The average age of the respondents was 26.5 . A percentage of $81.4 \%$ of the respondents were in their twenties and the rest of the respondents were under 20 and over 30 years. Approximately $32.5 \%$ of respondents were within 1-2 years of beginning mobile games. Validated measures were adopted from previous research. All responses to questions were made using a seven-point Likert type scale $(1=$ strongly disagree to $7=$ strongly agree $)$.

Table 3. Profile of respondents.

\begin{tabular}{cccc}
\hline Demographics & Categories & Number & Percentage \\
\hline \multirow{2}{*}{ Gender } & Male & 127 & $53.6 \%$ \\
& Female & 110 & $46.4 \%$ \\
\hline \multirow{2}{*}{ Age } & Less than 20 & 17 & $7.2 \%$ \\
& $21-25$ & 105 & $44.3 \%$ \\
& $26-30$ & 88 & $37.1 \%$ \\
& More than 31 & 27 & $11.4 \%$ \\
\hline \multirow{2}{*}{ MSNG usage period } & Less than 6 months & 61 & $25.7 \%$ \\
& 6 months-1 year & 22 & $9.3 \%$ \\
& $1-2$ years & 77 & $32.5 \%$ \\
& $2-3$ years & 31 & $13.0 \%$ \\
& $3-4$ years & 16 & $6.8 \%$ \\
& More than 4 years & 30 & $12.7 \%$ \\
\hline \multirow{2}{*}{ Daily MSNG usage time } & Less than $1 \mathrm{~h}$ & 71 & $30.0 \%$ \\
& $1-2 \mathrm{~h}$ & 108 & $45.6 \%$ \\
& $2-3 \mathrm{~h}$ & 36 & $15.1 \%$ \\
& More han $3 \mathrm{~h}$ & 22 & $9.3 \%$ \\
\hline
\end{tabular}




\subsection{Measurement}

A structural equation modeling approach was used. Convergent and discriminant validity of the measures were checked using confirmatory factor analysis used by the structural equation model in AMOS 25.0.

All the fit measures for the measurement model were acceptable. They demonstrate that the measurement model had a marginal fit to the data $\left(X^{2}=91.488\right.$ with $\mathrm{df}=67, p<0.05 . X^{2} / \mathrm{df}=1.764$, $\mathrm{GFI}=0.933$, AGFI $=0.896, \mathrm{CFI}=0.971$, RMSEA $=0.057)$. All indices exceeded acceptable levels. Tables 4 and 5 show the results for measurement model and discriminant analysis. The convergent validity was checked using factor loadings, Cronbach's alphas, composite reliability, and average variances extracted as shown in Table 4. Results of the measurement model were acceptable compared with the recommended values suggested by Hair et al. [64]. Discriminant validity was tested by comparing correlations against the squared root of the AVE. The Table 5 shows that all the AVE for all the constructs are higher than those for all related construct correlations. This shows that each construct was distinct from the other constructs.

Table 4. Measurement model.

\begin{tabular}{|c|c|c|c|c|c|c|}
\hline Construct & Items & Mean & Factor Loading & CR & AVE & Alpha \\
\hline \multirow{4}{*}{ Social Presence } & SOP1 & 5.44 & 0.872 & \multirow{4}{*}{0.889} & \multirow{4}{*}{0.667} & \multirow{4}{*}{0.886} \\
\hline & SOP2 & 5.70 & 0.832 & & & \\
\hline & SOP3 & 5.60 & 0.808 & & & \\
\hline & SOP4 & 5.35 & 0.749 & & & \\
\hline \multirow{3}{*}{ Perceived Enjoyment } & PEE1 & 5.02 & 0.873 & \multirow{3}{*}{0.871} & \multirow{3}{*}{0.694} & \multirow{3}{*}{0.859} \\
\hline & PEE2 & 4.84 & 0.904 & & & \\
\hline & PEE3 & 4.29 & 0.710 & & & \\
\hline \multirow{3}{*}{ Concentration } & CON1 & 4.94 & 0.692 & \multirow{3}{*}{0.867} & \multirow{3}{*}{0.668} & \multirow{3}{*}{0.852} \\
\hline & CON2 & 5.45 & 0.933 & & & \\
\hline & CON3 & 5.20 & 0.846 & & & \\
\hline \multirow{2}{*}{ Attitude } & ATT1 & 5.13 & 0.756 & \multirow{2}{*}{0.670} & \multirow{2}{*}{0.505} & \multirow{2}{*}{0.675} \\
\hline & ATT2 & 5.52 & 0.662 & & & \\
\hline \multirow{2}{*}{ Sustainable Use Intention } & SUI1 & 3.99 & 0.679 & \multirow{2}{*}{0.753} & \multirow{2}{*}{0.607} & \multirow{2}{*}{0.743} \\
\hline & SUI2 & 4.17 & 0.868 & & & \\
\hline
\end{tabular}

Table 5. Discriminant analysis.

\begin{tabular}{cccccc}
\hline Construct & $\mathbf{( 1 )}$ & $\mathbf{( 2 )}$ & $\mathbf{( 3 )}$ & (4) & (5) \\
\hline Social Presence (1) & 0.816 & & & & \\
Perceived Enjoyment (2) & 0.114 & 0.833 & & & \\
Concentration (3) & 0.263 & 0.470 & 0.817 & & \\
Attitude (4) & 0.260 & 0.483 & 0.547 & 0.710 & \\
Sustainable Use Intention (5) & 0.153 & 0.314 & 0.442 & 0.487 & 0.779 \\
\hline
\end{tabular}

Notes: The diagonal in the bold values represent the square root of AVE.

\subsection{Research Model and Testing of Hypothesis}

To test the proposed model and hypotheses, we used the structural equation model in AMOS 25.0. A structure equation model was adopted to test hypotheses proposed. All fit measures in the structural model had a marginal fit to the data $\left(X^{2}=95.308\right.$ with $\mathrm{df}=70, p=0.024$. $\mathrm{X}^{2} / \mathrm{df}=1.362, \mathrm{GFI}=0.947$, AGFI $=0.921$, CFI $=0.986$, RMSEA $=0.039)$. The Table 6 shows the results of testing research model and hypothesis. The results show that all hypotheses were supported. 
Table 6. Summary of results.

\begin{tabular}{cccc}
\hline Hypothesis & Path & Coefficients & $t$-Value \\
\hline H1 & Social presence-Perceived enjoyment & 0.162 & $2.548^{*}$ \\
H2 & Social presence-Concentration & 0.263 & $3.619^{* *}$ \\
H3 & Perceived enjoyment-Attitude & 0.607 & $6.640^{* *}$ \\
H4 & Concentration-Attitude & 0.341 & $4.252^{* *}$ \\
H5 & Concentration-Perceived enjoyment & 0.554 & $8.093^{* *}$ \\
H6 & Attitude-Sustainable use intention & 0.668 & $6.317^{* *}$ \\
\hline
\end{tabular}

Notes: ${ }^{*} p<0.01,{ }^{* *} p<0.001$.

As shown in Table 6, the confirmation of $\mathrm{H} 1$ and $\mathrm{H} 2$ suggests that users are more likely to have concentration and perceived enjoyment in mobile social network game if they perceive that mobile network game provides social presence.

Furthermore, the perceived enjoyment had a significant effect on the concentration and attitude towards mobile network game. We also found a significant positive relationship between concentration and attitude towards mobile network game. This provided support for hypotheses H3, H4, and H5.

H6 predicted positive relationship between attitude towards mobile games and sustainable use intention. The result shows that attitude towards mobile games had a significant positive effect on sustainable intention to use, providing support for $\mathrm{H} 6$.

\section{Discussion}

This research is mainly based on the perceived social presence of MSNGs combined with social software, and focuses on factors affecting the sustainable use intention of MSNGs. Most MSNGs developers believe that the ultimate goal of releasing a game and attracting players continuously is to encourage sustained benefits. Specifically, first of all, with the increasing dependence of modern people on mobile phones, social software based on mobile phones has become an indispensable means of communication for modern people. MSNGs not only realize the intimate combination of mobile games and SNS, but also attain sharing in the social network through entertainment together, so that all players experience the feeling of 'being with another'. Biocca et al. [65] defined this feeling as perceived social presence. In our study, we chose social presence as our dependent variable and proved that the social presence perceived by players in MSNGs has a positive impact on the sustainable use intention through a series of mediator variables. Second, the game product itself can easily lead to player addiction. Therefore, in this study, we use the flow theory-perceived enjoyment and concentration-as our mediator variables. Through a questionnaire, we confirmed that the social presence perceived by MSNGs has a positive impact on the player's perceived enjoyment and concentration in playing MSNGs. Finally, our survey confirms that the more enjoyment and concentration the player perceives in the MSNGs, the more positive attitude the player will have.

\subsection{Theoretical and Practical Implications}

The appeal and opportunity of the mobile application and mobile gaming market has attracted more entrepreneurs and innovators in the entertainment industry, as well as academic research focused on mobile social networking games. In our research, we suggest social presence as an important variable, and we study the factors affecting the continued use of MSNGs in order to contribute to both theory and practice.

From the theoretical standpoint, as people pay more and more attention to sociality, social presence has attracted strong research attention. This study offers a comprehensible measurement matrix that includes perceived social presence, perceived enjoyment, concentration, and attitude to the MSNGs, as well as the relationships among these factors. Based on the flow theory, this paper studies the effect of perceived social presence on perceived enjoyment and concentration for the first time from the 
viewpoint of social presence, and lays a foundation for the study on the contributing factor of social presence in flow experience among other fields.

The social network game companies and developers can frame the practical implications from this study. First, understanding the user's social presence factor has become crucial to the success of MSNGs. The users sustainably use the MSNGs not only because the MSNGs provide a social presence but also because it increases flow on games. The game developers need a better understanding concerning the level of social presence and its influence on user flow in MSNGs. They should also establish user flow in SNGs by ensuring that their services are based on users' social presence.

Secondly, until now, most mobile games are free, but as MSNG enters the mainstream market, game developers will soon monetize applications [14]. It is essential to capture user intention and provide the game service based on sustainable use intention. Game developers should put significant resources into establishing user concentration as well as developing and delivering enjoyable games. This study recommends that MSNGs designers to develop applications that encourage the SNG members to use such a platform continuously.

In conclusion, as users take MSNGs as a new way of enjoying and communicating with others through SNG, and as companies provide users with a platform, SNG could evolve into very effective application. To ensure their sustainable behavior, however, The MSNGs providers should focus on efforts to improve the level of sustainable use intention by enhancing the social presence and level of flow.

\subsection{Limitations and Future Research}

The study reviewed current literature and expanded upon it by developing and validating the model to investigate factors that contribute to the sustainable use intention of MSNGs. Nevertheless, the study has some limiting factors and some of the results need further research. First of all, the surveyed participants do not represent all age groups, as most players of MSNGs are still young. Thus, our study subjects are represented by young players. Hence, this study does not provide a comprehensive view of all MSNGs groups, but only of a subset of players. Second, males are more likely to play and prefer more violent games than females [66]. We mainly researched two mobile social networks games: Arena of Valor and the Player Unknown's Battlegrounds. Both games have achieved great success in the Chinese market and also attracted a large proportion of female players. According to data of Masters of media [67], Arena of Valor has 200 million users, of which 54\% are female. In this study, we did not consider any gender differences in playing MSNGs. Therefore, future research can study the gender variation in playing motivation. However, our study is meaningful because Arena of Valor and Player Unknown's Battlegrounds are favored by female players. Thirdly, we selected two games, Arena of Valor and the Player Unknown's Battlegrounds, which were introduced and developed into MSNGs by Tencent. The SNS platform, WeChat, which is commonly used by Chinese people, was also developed by Tencent. The success of these two games has important prerequisites: they can easily achieve and connect with the SNS platform which has more than one billion users. By connecting with social networks, mobile players have a strong perceived social presence, which becomes the most important independent variable in our research. However, other games attempting to enter the Chinese market must consider the high cost of cooperating with Tencent. Therefore, our research conclusions have practical limitations to some extent. As the final study limitation, for our sample selection we chose the Chinese market; therefore, our research results are not applicable to every country and region.

Author Contributions: Conceptualizing, collecting data, data curation, writing, H.W.; Conceptualizing, research methodology, formal analysis, review, K.L. All authors have read and agreed to the published version of the manuscript.

Funding: This research received no external funding.

Conflicts of Interest: The authors declare no conflict of interest. 


\section{References}

1. Choi, S. The flipside of ubiquitous connectivity enabled by smartphone-based social networking service: Social presence and privacy concern. Comput. Hum. Behav. 2016, 65, 325-333. [CrossRef]

2. Lee, J.; Suh, E.; Park, H.; Lee, S. Determinants of Users' Intention to Purchase Probability-Based Items in Mobile Social Network Games: A Case of South Korea. IEEE Access 2018, 6, 12425-12437. [CrossRef]

3. Park, E.; Baek, S.; Ohm, J.; Chang, H.J. Determinants of player acceptance of mobile social network games: An application of extended technology acceptance model. Telemat. Inform. 2014, 31, 3-15. [CrossRef]

4. Chen, C.; Leung, L. Are you addicted to Candy Crush Saga? An exploratory study linking psychological factors to mobile social game addiction. Telemat. Inform. 2016, 33, 1155-1166. [CrossRef]

5. Game Central. Candy Crush Saga Prepares 5000th Level and pLans for 10 More Years of Puzzles. Available online: https://metro.co.uk/2019/07/02/candy-crush-saga-prepares-5000th-level-and-plans-for-10more-years-of-puzzles-10104154/ (accessed on 2 July 2019).

6. Wei, P.S.; Lu, H.P. Why do people play mobile social games? An examination of network externalities and of uses and gratifications. Internet Res. 2014, 24, 313-331. [CrossRef]

7. Chen, H.; Rong, W.; Ma, X.; Qu, Y.; Xiong, Z. An Extended Technology Acceptance Model for Mobile Social Gaming Service Popularity Analysis. Mob. Inf. Syst. 2017, 3, 3906953. [CrossRef]

8. Jeon, H.; Ahn, H.J.; Yu, G.J. What makes people react to the posts on the brand pages of mobile social network games? Online Inf. Rev. 2016, 40, 435-448. [CrossRef]

9. Weibel, D.; Wissmath, B.; Habegger, S.; Steiner, Y.; Groner, R. Playing online games against computer- vs. human-controlled opponents: Effects on presence, flow, and enjoyment. Comput. Hum. Behav. 2008, 24, 274-2291. [CrossRef]

10. Bradshaw, T. How Shut-in Consumers Turned Mobile Gaming into a \$100-Billion Industry. Available online: https://financialpost.com/technology/gaming/how-shut-in-consumers-turned-mobile-gaming-into-a-100billion-industry (accessed on 1 July 2020).

11. Bachen, C.M.; Hernández-Ramos, P.; Raphael, C.; Waldron, A. How do presence, flow, and character identification affect players' empathy and interest in learning from a serious computer game? Comput. Hum. Behav. 2016, 64, 77-87. [CrossRef]

12. Park, S.B.; Hwang, H.S. Understanding online game addiction: Connection between presence and flow. In Proceedings of the Human-Computer Interaction. Interacting in Various Application Domains, 13th International Conference, HCI International 2009, San Diego, CA, USA, 19-24 July 2009; pp. 378-386. [CrossRef]

13. Alsén, A.; Runge, J.; Drachen, A.; Klapper, D. Play with me? Understanding and measuring the social aspect of casual gaming. Proc. AIIDE Play. Anal. Workshop 2016, 9, 115-121.

14. Shin, D.H.; Shin, Y.J. Why do people play social network games? Comput. Hum. Behav. 2011, $27,852-861$. [CrossRef]

15. China Games Market 2018. Available online: https://newzoo.com/insights/infographics/china-games-market2018/ (accessed on 3 August 2018).

16. Graziani, T. WeChat Impact Report 2018: All the Latest WeChat Data. Available online: https://walkthechat. com/wechat-impact-report-2016/ (accessed on 4 July 2018).

17. Short, J.; Williams, E.; Christie, B. The Social Psychology of Telecommunications; Wiley: New York, NY, USA, 1976.

18. Wei, J.; Seedorf, S.; Lowry, P.B.; Thum, C.; Schulze, T. How increased social presence through co-browsing influences user engagement in collaborative online shopping. Electron. Commer. Res. 2017, 24, 84-99. [CrossRef]

19. Animesh, A.; Pinsonneault, A.; Yang, S.B.; Oh, W. An odyssey into virtual worlds: Exploring the impacts of technological and spatial environments on intention to purchase virtual products. MIS Q. 2011, 35, 789-810. [CrossRef]

20. Tseng, F.C.; Huang, H.C.; Teng, C.I. How do online game communities retain gamers? Social presence and social capital perspectives. J. Comput.-Mediat. Commun. 2015, 20, 601-614. [CrossRef]

21. Richardson, J.C.; Swan, K. Examining social presence in online courses in relation to students' perceived learning and satisfaction. Online Learn. 2003, 7, 68-88. [CrossRef]

22. Park, S.W.; Cho, K.; Lee, B.G. What makes smartphone users satisfied with the mobile instant messenger?: Social presence, flow, and self-disclosure. Int. J. Multimed. Ubiquitous Eng. 2014, 9, 315-324. [CrossRef] 
23. Csikszentmihalyi, M.; LeFevre, J. Optimal experience in work and leisure. J. Pers. Soc. Psychol. 1989, 56, 815-822. [CrossRef]

24. Pelet, J.É.; Ettis, S.; Cowart, K. Optimal experience of flow enhanced by telepresence: Evidence from social media use. Inf. Manag. 2017, 54,115-128. [CrossRef]

25. Webster, J.; Trevino, L.K.; Ryan, L. The dimensionality and correlates of flow in human-computer interactions. Comput. Hum. Behav. 1993, 9, 411-426. [CrossRef]

26. Bakker, A.B. Flow among music teachers and their students: The crossover of peak experiences. J. Vocat. Behav. 2005, 66, 26-44. [CrossRef]

27. Park, S.W.; Oh, D.; Lee, B.G. Analyzing User Satisfaction Factors for Instant Messenger-Based Mobile SNS. In Future Information Technology; Springer: Berlin/Heidelberg, Germany, 2011; pp. 280-287.

28. Novak, T.P.; Hoffman, D.L.; Yung, Y. Measuring the Customer Experience in Online Environments: A Structural Modeling Approach. Mark Sci. 2000, 19, 22-42. [CrossRef]

29. Hoffman, D.L.; Novak, T.P. Flow Online: Lessons Learned and Future Prospects. J. Interact. Mark. 2009, 23, 23-34. [CrossRef]

30. Koufaris, M. Applying the Technology Acceptance Model and Flow Theory to Online Consumer Behavior. Inf. Syst. Res. 2002, 13, 205-223. [CrossRef]

31. Chiang, Y.T.; Lin, S.S.J.; Cheng, C.Y.; Liu, E.Z.F. Exploring online game players' flow experiences and positive affect. Turk. Online J. Educ. Technol. 2011, 10, 106-114.

32. O'Cass, A.; Carlson, J. Examining the effects of website-induced flow in professional sporting team websites. Internet Res. 2010, 20, 115-134. [CrossRef]

33. Trevino, L.K.; Webster, J. Flow in computer-mediated communication: Electronic mail and voice mail evaluation and impacts. Commun. Res. 1992, 19, 539-573. [CrossRef]

34. Ghani, J.A.; Deshpande, S.P. Task characteristics and the experience of optimal flow in human-computer interaction. J. Psychol. Prov. Mass Etc. 1994, 128, 381-391. [CrossRef]

35. Li, D.; Browne, G.J.; Wetherbe, J.C. Why Do Internet Users Stick with a Specific Web Site? A Relationship Perspective. Int. J. Electron. Commer. 2006, 10, 105-141. [CrossRef]

36. Zhou, T.; Lu, Y. Examining mobile instant messaging user loyalty from the perspectives of network externalities and flow experience. Comput. Hum. Behav. 2010, 27, 883-889. [CrossRef]

37. Yan, Y.; Davison, R.M.; Mo, C. Employee creativity formation: The roles of knowledge seeking, knowledge contributing and flow experience in Web 2.0 virtual communities. Comput. Hum. Behav. 2013, 29, 923-1932. [CrossRef]

38. Su, Y.S.; Chiang, W.L.; Lee, C.T.J.; Chang, H.C. The effect of flow experience on player loyalty in mobile game application. Comput. Hum. Behav. 2016, 63, 240-248. [CrossRef]

39. Ettis, S.A. Examining the relationships between online store atmospheric colors, flow experience and consumer behavior. J. Retail. Consum. Serv. 2017, 37, 43-55. [CrossRef]

40. Gao, L.; Bai, X. An empirical study on continuance intention of mobile social networking services: Integrating the IS success model, network externalities and flow theory. Asia Pac. J. Mark. Logist. 2014, 26, 168-189. [CrossRef]

41. Jung, Y.; Perez-Mira, B.; Wiley-Patton, S. Consumer adoption of mobile TV: Examining psychological flow and media content. Comput. Hum. Behav. 2009, 25, 123-129. [CrossRef]

42. Bulu, S.T. Place presence, social presence, co-presence, and satisfaction in virtual worlds. Comput. Educ. 2012, 58, 154-161. [CrossRef]

43. Lee, H.G.; Chung, S.; Lee, W.H. Presence in virtual golf simulators: The effects of presence on perceived enjoyment, perceived value, and behavioral intention. New Media Soc. 2013, 15, 930-946. [CrossRef]

44. Heeter, C. Communication Research on Consumer VR. Commun. Age Virtual Real. 1995, 1, 191-218.

45. Sweetser, P.; Wyeth, P. Game Flow: A model for evaluating player enjoyment in games. Comput. Entertain. 2005, 3, 1-24.

46. Liu, Y.; Li, H. Exploring the impact of use context on mobile hedonic services adoption: An empirical study on mobile gaming in China. Comput. Hum. Behav. 2011, 27, 890-898. [CrossRef]

47. Moon, J.W.; Kim, Y.G. Extending the tam for a world-wide-web context. Inf. Manag. 2001, 38, $217-230$. [CrossRef]

48. Jin, S.A.A. I feel present-Therefore, I experience flow: A structural equation modeling approach to flow and presence in video games. J. Broadcast. Electron. Media 2011, 55, 114-136. [CrossRef] 
49. Steuer, J. Defining virtual reality: Dimensions determining telepresence. J. Commun. 1992, 42, 73-93. [CrossRef]

50. Chang, I.C.; Liu, C.C.; Chen, K. The effects of hedonic/utilitarian expectations and social influence on continuance intention to play online games. Internet Res. 2014, 24, 21-45. [CrossRef]

51. Ha, I.; Yoon, Y.; Choi, M. Determinants of adoption of mobile games under mobile broadband wireless access environment. Inf. Manag. 2007, 44, 276-286. [CrossRef]

52. Choe, P.; Schumacher, D. Influence of Different Types of Vibrations on Technical Acceptance of a Mobile Game Aiming for Hedonic Satisfaction. Int. J. Hum.-Comput. Interact. 2015, 31, 33-43. [CrossRef]

53. Wu, J.; Liu, D. The effects of trust and enjoyment on intention to play online games. J. Electron. Commer. Res. 2007, 8, 128-140.

54. Lu, Y.; Zhou, T.; Wang, B. Exploring Chinese users' acceptance of instant messaging using the theory of planned behavior, the technology acceptance model, and the flow theory. Comput. Hum. Behav. 2009, 25, 29-39. [CrossRef]

55. Lee, M.C. Explaining and predicting users' continuance intention toward e-learning: An extension of the expectation-confirmation model. Comput. Educ. 2010, 54, 506-516. [CrossRef]

56. Wu, H.L. An integrated framework of SNS users' motivations. In Proceedings of the 15th Americas Conference on Information Systems, AMCIS 2009, San Francisco, CA, USA, 6-9 August 2009; p. 379.

57. Chinchanachokchai, S.; Duff, B.R.L.; Sar, S. The effect of multitasking on time perception, enjoyment, and ad evaluation. Comput. Hum. Behav. 2015, 45, 185-191. [CrossRef]

58. Guo, Z.; Xiao, L.; Van Toorn, C.; Lai, Y.; Seo, C. Promoting online learners' continuance intention: An integrated flow framework. Inf. Manag. 2015, 53, 279-295. [CrossRef]

59. Lin, K.M. E-learning continuance intention: Moderating effects of user e-learning experience. Comput. Educ. 2011, 56, 515-526. [CrossRef]

60. Praveena, K.; Thomas, S. Continuance intention to use Facebook: A study of perceived enjoyment and TAM. Bonfring Int. J. Ind. Eng. Manag. Sci. 2014, 4, 24-29.

61. Hsiao, C.C.; Chiou, J.S. The effects of a player's network centrality on resource accessibility, game enjoyment, and continuance intention: A study on online gaming communities. Electron. Commer. Res. Appl. 2012,11, 75-84. [CrossRef]

62. Hossain, M.A.; Kim, M. Does Multidimensional Service Quality Generate Sustainable Use Intention for Facebook? Sustainability 2018, 10, 2283. [CrossRef]

63. Si, H.; Shi, J.; Tang, D.; Wu, G.; Lan, J. Understanding intention and behavior toward sustainable usage of bike sharing by extending the theory of planned behavior. Resour. Conserv. Recycl. 2020, 152, 104513. [CrossRef]

64. Hair, J.F., Jr.; Black, W.C.; Babin, B.J.; Anderson, R.E.; Tatham, R.L. SEM: An introduction. Multivar. Data Anal. 2010, 5, 629-686.

65. Biocca, F.; Harms, C.; Burgoon, J.K. Toward a more robust theory and measure of social presence: Review and suggested criteria. Presence Teleoperators Virtual Environ. 2003, 12, 456-480. [CrossRef]

66. Eastin, M.S.; Griffiths, R.P. Beyond the shooter game: Examining presence and hostile outcomes among male game players. Commun. Res. 2006, 33, 448-466. [CrossRef]

67. Zhang, C.Y. 'Arena of Valor': World's Top Grossing Mobile Game is an Auxiliary Tool of Social Network. Available online: https://mastersofmedia.hum.uva.nl/blog/2017/09/24/arena-of-valor-worlds-top-grossingmobile-game-is-an-auxiliary-tool-of-social-network/ (accessed on 24 September 2017).

(C) 2020 by the authors. Licensee MDPI, Basel, Switzerland. This article is an open access article distributed under the terms and conditions of the Creative Commons Attribution (CC BY) license (http://creativecommons.org/licenses/by/4.0/). 